\title{
Optimization of the Thermal and Mechanical Behavior of an Aeronautical Brake Disc using the Design of Experiments Approach
}

\author{
A. LABDI*, M. BOUCHETARA** \\ *Faculty of Mechanical Engineering, USTO University, L.P 1505, El-Menaouer, USTO 31000 Oran, Algeria, \\ E-mail: tribostudent@gmail.com \\ **Faculty of Mechanical Engineering, USTO University, L.P 1505, El-Menaouer, USTO 31000 Oran, Algeria \\ E-mail: mbouchetara@hotmail.com
}

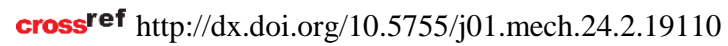

\section{Introduction}

The design of brake discs has been the subject of numerous studies. Indeed, the effectiveness of the brakes and thus the safety of the passengers significantly depend on the design of the braking system. In order to understand mechanical and thermal behavior of brake disc, many experimental studies have been conducted to measure brake disc temperature distribution and thermal stress [1-3]. Noting also that the FE approach is widely employed in solving such as problems related to braking phase $[4,5]$.

According to the previous research, it has been found that the following factors affect the brake disc behavior: braking mode: single, emergency and repeated brake; the shape of the disc: full or ventilated, thickness variation and hole number; material properties: disc, pad [6-8]. A statistical design of experiments approach has indicated that the number of braking applications has the strongest effect on the interface temperatures in comparison with other factors, i.e. friction loads, sliding speeds and friction material composition [9].

To examine the influence and the interactions of different parameters characterizing a brake disc on the thermal and mechanical behavior, we adopted the design of experiments method (DOE). This statistical optimization technique very useful in parametric analysis allows to obtain the analytical model which describes the relationship between the main parameters, their interactions and the response (the temperature or the mechanical constraints). According to the established mathematical model, the experimenter can thus deduce qualitative or quantitative information on the behavior of the object studied. proach:

In the present study, we adopted the following ap-

a) Determination of the temperature distribution and equivalent stress for different geometrical brake disc configurations (Fig. 1) during the braking phase using the FE commercial software ANSYS 14.5, and

b) Application of the experimental design method to get the mathematical model describing the thermal or mechanical behavior of the brake disc, followed by the analysis of the variance (ANOVA test) in order to confirm the significant effects of the selected parameters on the response.

In general, the experimental design method serves to establish a relationship between two types of variables; the response as output variable (temperature or mechanical stress) and the factors which are physical variables modifiable by the experimenter, assumed to influence the variation of the response these factors can be continuous (thickness, diameter, etc.); discrete (holes number) or qualitative (type of discs or the characteristic of the material used).

The aircraft brake disc selected for this study and its variants are shown in Fig. 1 and in Fig. 2 respectively. Table 1 illustrate the variables chosen to establish the design of experiments and the level of each factor.

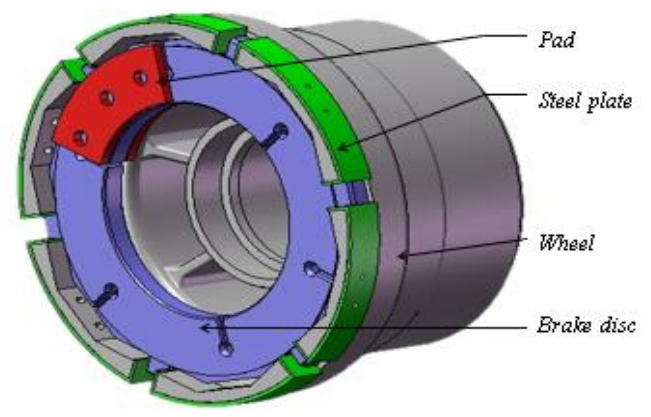

Fig. 1 Aircraft brake disc [10]

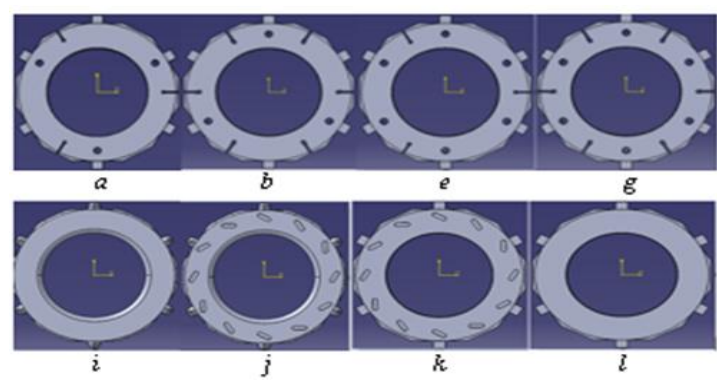

Fig 2 View of different disc configurations

Table 1

Design modifications of the brake disc

\begin{tabular}{|l|c|c|c|c|c|}
\hline $\begin{array}{l}\text { Eactors } \\
\text { Levels }\end{array}$ & $x_{1}$ & $x_{2}$ & $x_{3}$ & $x_{4}$ & $x_{5}$ \\
\hline Low (-) & 8 & 3 & 3 & No & yes \\
\hline High (+) & 12 & 6 & 6 & yes & no \\
\hline $\begin{array}{l}x_{1}: \text { thickness, mm; } x_{2}: \text { slit number; } x_{3}: \text { hole number } \\
x_{4}: \text { holes in the disc; } x_{5}: \text { external shape }\end{array}$
\end{tabular}

\section{Thermal modeling}

Table 2 gives the values of the parameters required to calculate the brake speed $V_{h}$, the initial angular velocity of brake disc $\omega_{0}$ and the heat flux $q_{\text {inst }}(t)$ [11]. Brake speed:

$$
V_{i}=V_{b}-a * t, \mathrm{~m} / \mathrm{s}
$$


Heat flux:

$$
q_{\text {inst }}(\mathrm{t})=681902-75630.48 * t, \mathrm{w} / \mathrm{m}^{2}
$$

Table 2

Values of main simulation parameters

\begin{tabular}{|l|l|}
\hline Total braking time $t_{b}, \mathrm{~s}$ & 9.00 \\
\hline Time step $\Delta t, \mathrm{~s}$ & 0.01 \\
\hline Initial time $t_{i}, \mathrm{~s}$ & 0 \\
\hline Aircraft weight $m, \mathrm{~kg}$ & 1050 \\
\hline Initial speed of landing $V_{i}, \mathrm{~m} / \mathrm{s}$ & 28.00 \\
\hline Aircraft deceleration dec, $\mathrm{m} / \mathrm{s}^{2}$ & 3.00 \\
\hline Braking distance $L_{b}, \mathrm{~m}$ & 130 \\
\hline Wheel radius $r, \mathrm{~m}$ & 0.42 \\
\hline Flux distribution rate $k$ & 0.4 \\
\hline Contact surface (disc/pad) $A_{d}, \mathrm{~mm} 2$ & 13194.68 \\
\hline Applied force on the disc $F_{d}, \mathrm{~N}$ & 1512 \\
\hline
\end{tabular}

2.1. The convective heat transfer coefficient $(h=h(t))$

In the thermal modeling, the convective heat transfer coefficient $h=h(t)$, is first determined on each free surface of the disc using Ansys CFX. This parameter will then be used to calculate the disc temperature, Figs. 3 and 4 show respectively the half of the full disc with 8 convective heat exchange surfaces and the air domain. For computing this coefficient, we consider the following conditions:

- The fluid domain: ambient air at $25^{\circ} \mathrm{C}$.

- Reference pressure of $1 \mathrm{~atm}$ with a variation of speed.

- Turbulent flow of shear stress transport type.

- The solid domain: disc with a variable angular speed.

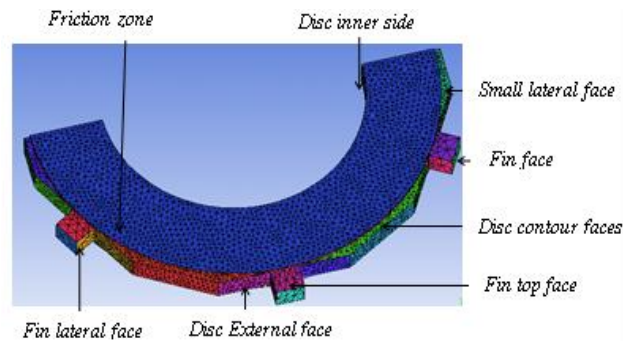

Fig. 3 Faces nomenclature of half full brake disc

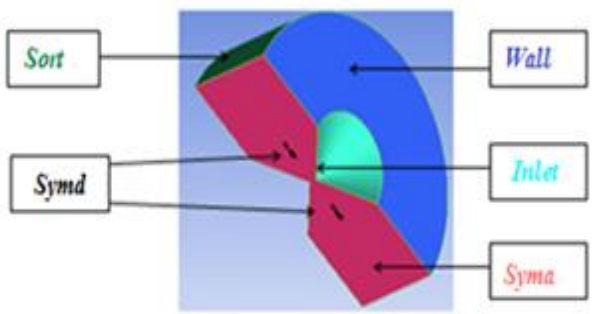

Fig. 4 Air domain representation

INLET - air inlet. SYMA - symetrical faces of air domain. $S Y M D$ - symetrical face of the disc. WALL - lateral symetrical faceof the air domain. SORT-air outlet.

The distribution of the computed convective heat transfer coefficient of the disc is visualised in Fig. 5.

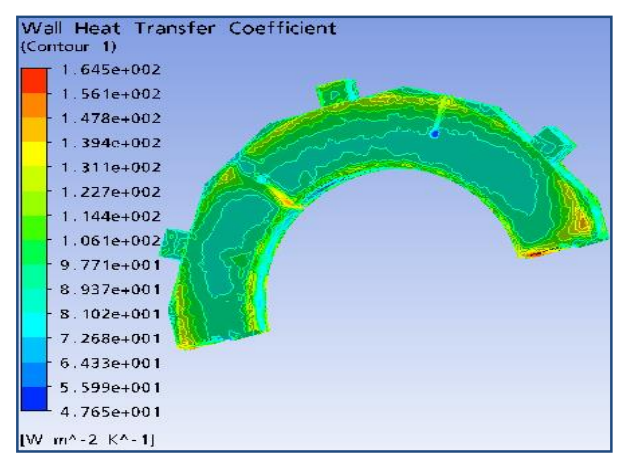

Fig. 5 Visualization of heat transfer coefficient

\subsection{Temperature calculation}

The simulation is carried out for all disc variants presented previously, while respecting the boundary conditions using the convection coefficients obtained for each variant and the heat flux, Fig. 5. For each simulation, the maximum value of the temperature is recorded. As example, Figs. 6-9 show respectively the temperature distribution for the variants $(j)$ and $(k)$.

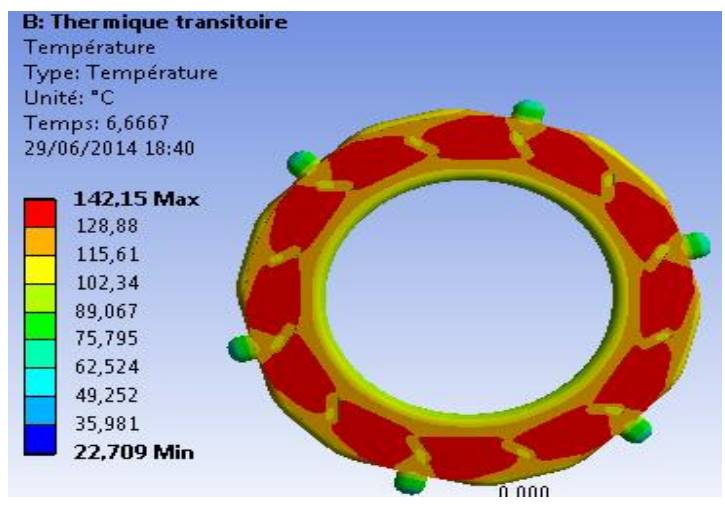

Fig. 6 Temperature distribution of disc $(j)$ at $t=6.67 \mathrm{~s}$

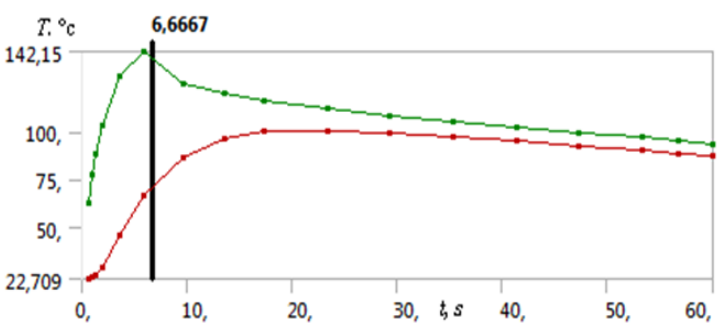

Fig. 7 Temperature of disc $(j)$ versus braking time

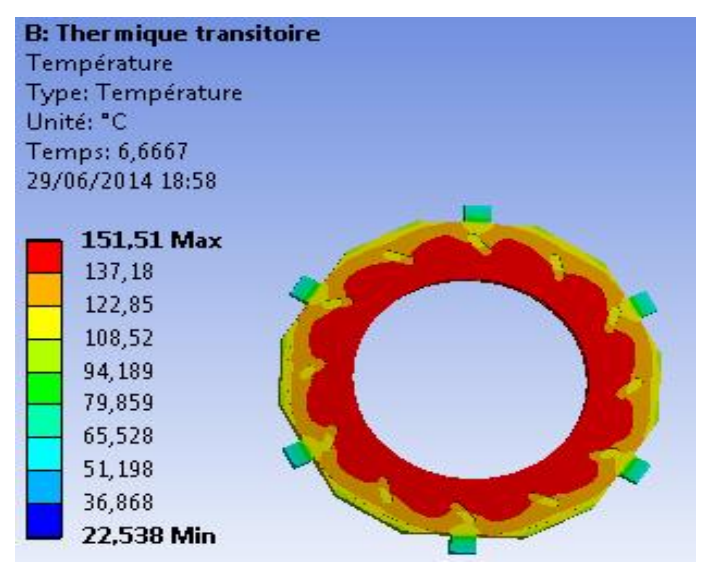

Fig. 8 Temperature distribution of disc $(k)$ at $t=6.67 \mathrm{~s}$ 


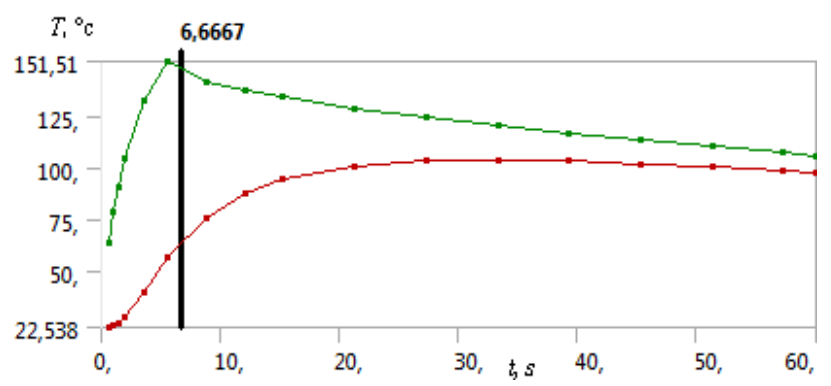

Fig. 9 Temperature of disc $(k)$ versus braking time

\section{Mechanical behavior modeling}

In this part, we determine the mechanical stress distribution of the previous two disc variants indicating their maximum values under the following boundary conditions:

- $\quad$ Right pad is fixed.

- Angular velocity of the disc $\omega_{t}=132 \mathrm{rad} / \mathrm{s}$.

- Pressure applied to the pad is $p=1.72 \mathrm{MPa}$.

- The fins considered as a fixed support.

Material specifications [12]: Disc in cast iron FG

25 AL. Pads material with the following characteristics:

- Young's modulus: $E=1000 \mathrm{MPa}$.

- Density: $\rho=1400 \mathrm{~kg} / \mathrm{m}^{3}$.

- Poisson coefficient: $v=0.25$.

- Friction coefficient: $\mu=0.2$.

Figs. 10 and 11 show respectively the Von-Mises stress distribution for the disc $(J)$ and $(K)$.

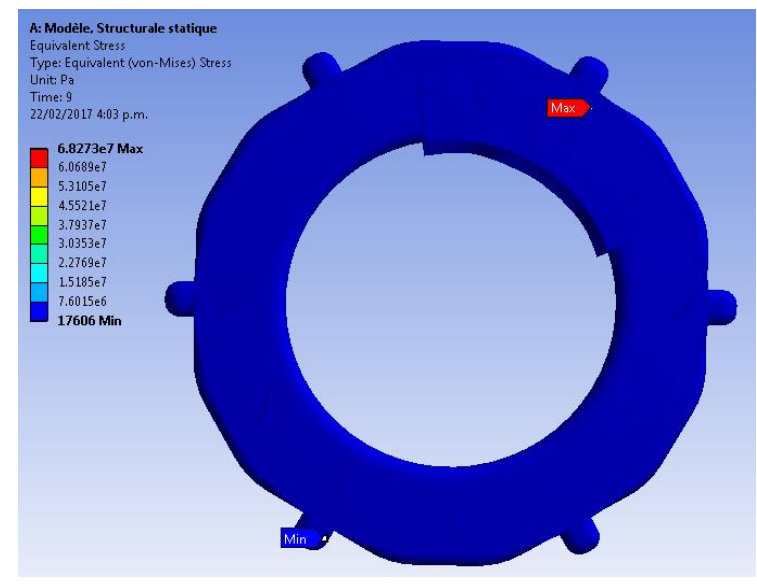

Fig. 10 Von-Mises stress distribution for the disc $(J)$

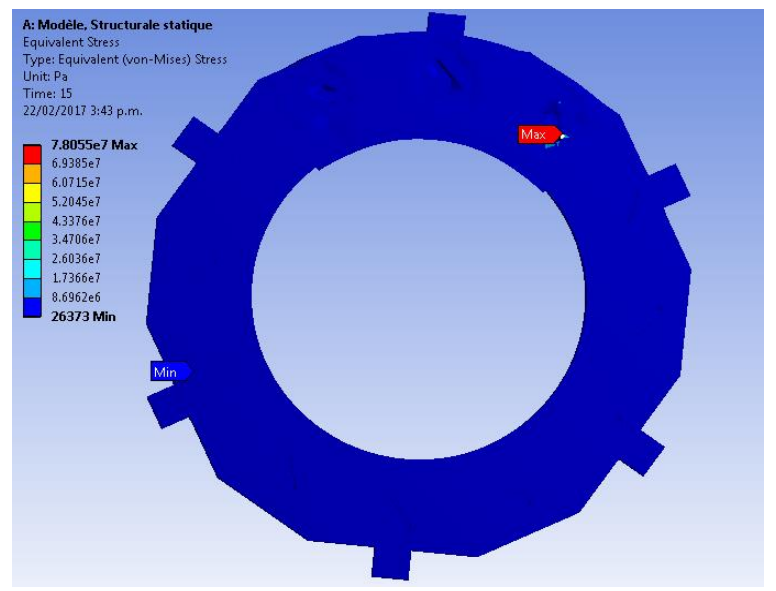

Fig. 11 Von-Mises stress distribution for the disc $(K)$

\section{DOE Application}

Since the objective of this study is the thermal and mechanical behavior optimization of the brake discs, we applied two types of DOE, full factorial design Tables 3, 4, 8 and fractional factorial design Tables 6 and 7.

From Table 3, we note that the effect of the factor $X_{I}$ (thickness) on the response (temperature) is about three times the factor $X_{2}$ (slit number). The factor $X_{3}$ (hole number) and the interaction effects $X_{1} X_{2}, X_{1} X_{3}, X_{2} X_{3}$ and $X_{1} X_{2}$ $X_{3}$ are negligible so the analytical model of the disc temperature is:

$$
T=98-9.86 X_{1}-2.6 X_{2}
$$

According to this model, the maximum temperature $T_{\max }=110.46^{\circ} \mathrm{C}$ is obtained at the low levels $X(-1,-1)$ and the minimum temperature $T_{\min }=85.54^{\circ} \mathrm{C}$ at the high levels $X(1,1)$, Fig. 5. This means that with the increase in the thickness and the number of slits, it is possible to improve the thermal behavior of the brake disc.

In Table 4, the effect of the factor $X_{2}$ (slits number) is the largest compared to others factors; its impact on the response (Von Mises stress) is nearly double the effect of $X_{1}$ and $X_{3}$. Less stress in this design is recorded in the $6^{\text {th }}$ experience. Noting that there is a high stress concentration in the slit areas, which means that the increase in the slit number favors the appearance of rupture zones. By referring to the full factorial design, Table 4, the analytical stress model can be written as follow:

$$
\begin{aligned}
& \sigma=32.54-5.31 X_{1}-8.42 X_{2}+3.54 X_{3}- \\
& -3.44 X_{1} X_{2}-1.19 X_{1} X_{3}+2.68 X_{2} X_{3} .
\end{aligned}
$$

According to the effect matrix of the fractional design for the factors $X_{1}, X_{2}, X_{3}$, Table 5, we consider only the first four experiences 5, 2, 3 and 8. It results the following fractional designs, Tables 6 and 7. These Tables do not allow the calculation of the interaction between the main factors. The effects calculated in fractional factorial designs are aliased:

$$
1^{\prime}=1+23 \quad 2^{\prime}=2+13 \quad 3^{\prime}=3+12 .
$$

This means that they do not directly reflect the effect of the factors taken individually but in groups of factors and interactions. It is sometimes impossible to conclude on the effect of a factor, since in contrast each term can be influential.

Polynomials for both fractional factorial designs are almost the same as full factorial designs:

$$
\begin{aligned}
& T=96.75-9.59 X_{1}-2.6 X_{2} ; \\
& \sigma=32.55-2.63 X_{1}+7.23 X_{2} .
\end{aligned}
$$

A fractional design with a reduced number of experiments gives an analytical model of the thermal behavior comparable to that obtained with a Full design. However, in the case of mechanical behavior, one notes that there is a certain deviation between the both experimental designs. 
Now considering the full design with the factors $X_{4}$ and $X_{5}$, Table 8 . From this design, the impact of the external face (factor $X_{5}$ ) is predominant:

Table 3

Full factorial design $2^{3}$ (Temperature as a response)

\begin{tabular}{|c|c|c|c|c|c|c|c|c|c|}
\hline Treatments & Average & \multicolumn{3}{|c|}{ Factors } & \multicolumn{4}{c|}{ Interactions } & Response \\
\hline$N^{0}$ & $Y_{0}$ & $X_{1}$ & $X_{2}$ & $X_{3}$ & $X_{1} X_{2}$ & $X_{1} X_{\underline{3}}$ & $X_{2} X_{3}$ & $X_{1} X_{2} X_{3}$ & $T,{ }^{0} \mathrm{C}$ \\
\hline 1 & + & - & - & - & + & + & + & - & 110.83 \\
\hline 2 & + & + & - & - & - & - & + & + & 88.94 \\
\hline 3 & + & - & + & - & - & + & - & + & 103,59 \\
\hline 4 & + & + & + & - & + & - & - & - & 84,67 \\
\hline 5 & + & - & - & + & + & - & - & + & 109.09 \\
\hline 6 & + & + & - & + & - & + & - & - & 89.67 \\
\hline 7 & + & - & + & + & - & - & + & - & 104.06 \\
\hline 8 & + & + & + & + & + & + & + & + & 85.38 \\
\hline Effects & 98 & -9.86 & -2.6 & -0.02 & 0.47 & 0.34 & 0.27 & -0.27 & \multicolumn{2}{c}{} \\
\hline
\end{tabular}

Table 4

Full factorial design $2^{3}$ (Stress as response)

\begin{tabular}{|c|c|c|c|c|c|c|c|c|c|}
\hline Treatments & Average & \multicolumn{3}{|c|}{ Factors } & \multicolumn{3}{c|}{ Interactions } & Response \\
\hline$N^{0}$ & $Y_{0}$ & $X_{1}$ & $X_{2}$ & $X_{3}$ & $X_{1} X_{2}$ & $X_{1} X_{\underline{3}}$ & $X_{2} X_{3}$ & $X_{1} X_{2} X_{3}$ & $\sigma, \mathrm{MPa}$ \\
\hline 1 & + & - & - & - & + & + & + & - & 23.90 \\
\hline 2 & + & + & - & - & - & - & + & + & 22.61 \\
\hline 3 & + & - & + & - & - & + & - & + & 42.34 \\
\hline 4 & + & + & + & - & + & - & - & - & 27.15 \\
\hline 5 & + & - & - & + & + & - & - & + & 28.03 \\
\hline 6 & + & + & - & + & - & + & - & - & 21.94 \\
\hline 7 & + & - & + & + & - & - & + & - & 57.13 \\
\hline 8 & + & + & + & + & + & + & + & + & 37.24 \\
\hline Effects & 32.54 & -5.31 & 8.9 & 4.49 & -2.49 & -0.22 & 2.67 & 0 & \\
\hline
\end{tabular}

Table 5

Table 7

Fractional design $2^{3-1}(I=123)$ for $y=T$

\begin{tabular}{|c|c|c|c|c|c|}
\cline { 2 - 6 } \multicolumn{1}{c|}{} & \multicolumn{4}{c|}{ Factors } & $\begin{array}{l}\text { Re- } \\
\text { sponse }\end{array}$ \\
\hline $\begin{array}{c}\text { Exp. } \\
\mathrm{N}^{\circ}\end{array}$ & $I$ & $X_{1}$ & $X_{2}$ & $X_{3}$ & $T,{ }^{0} \mathrm{C}$ \\
\hline 5 & + & - & - & + & 109.09 \\
2 & + & + & - & - & 88.84 \\
3 & + & - & + & - & 103.59 \\
8 & + & + & + & + & 85.38 \\
\hline Effects & 96.75 & -9.59 & -2.26 & 0.48 & \\
& & & & & \\
\cline { 1 - 5 } & & & &
\end{tabular}

Fractional design $2^{3-1}(I=123)$ for $Y=\sigma$

\begin{tabular}{|c|c|c|c|c|c|}
\cline { 2 - 6 } \multicolumn{1}{c|}{} & \multicolumn{4}{c|}{ Factors } & $\begin{array}{l}\text { Re- } \\
\text { sponse }\end{array}$ \\
\hline Exp. $\mathrm{N}^{\circ}$ & $I$ & $X_{1}$ & $X_{2}$ & $X_{3}$ & $\begin{array}{c}Y=\sigma, \\
M P a\end{array}$ \\
\hline 5 & + & - & - & + & 28.03 \\
2 & + & + & - & - & 22.61 \\
3 & + & - & + & - & 42.34 \\
8 & + & + & + & + & 37.24 \\
\hline Effects & 32.55 & -2.63 & 7.23 & 0.08 & \\
& & & & &
\end{tabular}

Full design $2^{2}$ (temperature as response)

\begin{tabular}{|c|c|c|c|c|c|}
\cline { 2 - 6 } \multicolumn{1}{c|}{} & \multicolumn{4}{c|}{ Factors and interaction } & $\begin{array}{l}\text { Re- } \\
\text { sponse }\end{array}$ \\
\hline Exp. N & $X_{4}$ & $X_{5}$ & $X_{4} X_{5}$ & $Y_{0}$ & $Y=$ Tmax \\
\hline 1 & - & - & + & + & 93,79 \\
2 & + & - & - & + & 90.44 \\
3 & - & + & - & + & 105.83 \\
4 & + & + & + & + & 108.27 \\
\hline Effects & $-0,23$ & 7.47 & 1.45 & 99,58 & \multicolumn{1}{c}{} \\
& & & & &
\end{tabular}

\section{Analysis of variance (ANOVA)}

The values of the responses obtained in the design of experiments must be analyzed to measure the influence of factors and interactions on the observed variations in the response. The main method for this purpose is the analysis of variance (ANOVA). In general, the ANOVA includes the calculation of mean squares of factors and interactions, residual variance and Fisher's test [13].

The variance of the factors is the sum of the squared deviations ( $S S D$ ) divided by the number of degrees of freedom $d f_{F}$ associated with the considered factor $F$. The sum of squared deviations associated with the factor $F$ is: 


$$
S S D_{F}=\frac{N}{N_{n i}} \sum_{i=1}^{N n i}\left(E_{F F=i}\right)^{2}=\frac{N}{N_{n i}} \sum_{i=1}^{N n i}\left(\bar{y}_{i}+\bar{y}\right)^{2},
$$

With:

$$
\bar{y}_{i}=\frac{1}{N} \sum_{i=1}^{N} y_{i}
$$

where $\bar{y}$ is average response; $\bar{y}_{i}$ is the mean of the responses observed for the experiments, where the factor $F$ takes its $i^{\text {th }}$ level.

For interactions involving factors $A$ and $B$, the sum of the squares of the deviations is equal to:

$$
S S D_{f g}=\frac{N}{N n_{i A . N n_{i B}}} \sum_{i=1}^{N n i} \sum_{j=1}^{N n i j}\left(\bar{y}_{i j}-\bar{y}_{i}-\bar{y}_{j}+\bar{y}\right)^{2},
$$

where $\bar{y}_{i j}$ is the mean of the responses where the factor $A$ takes its $i^{\text {th }}$ level, and where the factor $B$ takes its $j^{\text {th }}$ level.

The value of the mean squares, associated with the considered factor or interaction $x$ is:

$$
M S D_{x}=\frac{S S D_{x}}{d f_{x}}
$$

The calculation of the residual variance $M S D r$ is the sums of squared deviations (SSD) and the numbers of degrees of freedom $(d f)$ related to the selected interactions it is used to test the significance of the factors and to assess the quality of the model obtained.

\subsection{Fisher-Snedecor test}

Fisher test is a statistical hypothesis test to check the equality of two variances by verifying their ratio does not exceed certain theoretical value. We calculate the following ratio for a factor $\mathrm{x}$ considered as:

$$
F_{o b s}=\frac{\operatorname{MSD}_{x}}{\operatorname{MSDr}_{\mathrm{r}}}
$$

Where $F_{o b s}$ is calculated value of Fisher.

In inferential statistics, the term "null hypothesis" often denoted $H_{0}$ is usually refers to a general statement or default position that there is no relationship between two measured phenomena, or no association among groups [14]. It is generally assumed true until evidence indicates otherwise. The $H_{0}$ hypothesis must be rejected at level $\alpha$ if:

$$
p\left(F \geq F_{o b s}\right) \leq \alpha .
$$

We have applied ANOVA test for Table 3, we obtained the following Table 8 .

From Fisher Snedecor table the theoretical value $F_{t h}$ for $\left(n_{1}=1, n_{2}=4\right)$ and $\alpha=0.01$, is $F_{t h}=21.2$. Applying Fisher-test to ANOVA results, Table 8, we conclude that the factors $X_{1}$ and $X_{2}$ are significant about $99 \%$. We have only $1 \%$ risk of rejecting assumptions of equality with the residual variance. However, the factor $X_{3}$ is non- significant. We

\begin{tabular}{|c|c|c|c|c|}
\hline$X_{i}$ & $d f$ & $S S D i$ & $M S D$ & Fobs \\
\hline$X_{1}$ & 1 & 777.76 & 777.76 & 810.17 \\
\hline$X_{2}$ & 1 & 54.08 & 54.08 & 56.33 \\
\hline$X_{3}$ & 1 & 0.003 & 0.003 & 0.003 \\
\hline $\begin{array}{l}\text { Residual } \\
\text { variation }\end{array}$ & 4 & 3.85 & 0.96 & \\
\hline Total & 7 & 835.7 & & \\
\hline
\end{tabular}

refer to Table. 3 to see how these two factors affect the response $T$. We read that the less temperature is recorded when $X_{1}, X_{2}$ take their maximum values $(+)$.

Table 8

Variance analysis of design $2^{3}$ (response T)

The same procedure for mechanical investigation. From Table 4, we get the ANOVA results, Table 9.

Table 9

Variance analysis of design $2^{3}$ (response $\sigma$ )

\begin{tabular}{|c|c|c|c|c|c|}
\hline$X_{i}$ & $d f$ & $S S D i$ & $M S D$ & $F_{\text {obs }}$ & $F_{\text {theo }}$ \\
\hline$X_{1}$ & 1 & 225.36 & 225.36 & 5.38 & 7.71 \\
\hline$X_{2}$ & 1 & 567.17 & 567.17 & 13.6 & 7.71 \\
\hline$X_{3}$ & 1 & 100 & 100 & 2.39 & 7.71 \\
\hline $\begin{array}{c}\text { Residual } \\
\text { variation }\end{array}$ & 4 & 167.41 & 41.85 & \multicolumn{3}{|l}{} \\
\hline Total & 7 & 1055.94 & \multicolumn{4}{|l}{} \\
\hline
\end{tabular}

$F_{t h}=7.71$ for $n_{1}=1, n_{2}=4$ and $\alpha=0.05$. From Table 9 , we note that the factor $X_{2}$ is significant about $95 \%$. We have only $5 \%$ risk of disproving the null hypothesis. This analysis excludes the factor $X_{1}$ from the mechanical study. As in the thermal case of the analysis of variance, the factor $X_{3}$ (number of holes) is not significant. We also observe that the results obtained by the fractional designs are approximately same as those of full designs, Tables 5 and 6.

We made further changes on the outer shape of the disc but with a reduced number of simulations. From Table.8, we get:

$$
\operatorname{SSD} X_{4}=0.21, \operatorname{SSD} X_{5}=223.2, \operatorname{SSD}_{4} X_{5}=8.41 \text {. }
$$

For this full factorial design $2^{2}$ the theoretical value of the limiting effect is [15]:

$$
E_{f l i m}=\sqrt{\left(F_{t h} * S S D_{r} * d f f / N * d f_{r}\right)}
$$

$F_{\text {th }}$ corresponding to this design (Table.7) with $\alpha=$ 0.05 is equal to 161.45 . Hence, the value of the limiting effect $E_{f, \text { im }}=18.42$. We found that the effect of these changes of form would seem to be the most important, although this value has not depreciated a calculated value called limiting effect. Thereby, with a reduced number of experiments the significance of a given factor could not occur, although it is considered important.

\section{Conclusions}

Through this study, in order to understand the influence of certain geometrical parameters on the thermal and mechanic behavior, an aeronautical brake disc was 
taken making some modifications, we found that each variant behaves thermally and mechanically different, to determine what are the factors influencing this behavior, the experimental design method was applied, it allowed us to make three full factorial designs and two fractional designs, it was possible also to write a mathematical model for each of these designs; with ANOVA and Fisher test it was found that among the factors selected in this study, the thickness and the slit number were the most influential factors for the thermal performance of the disc. However, for mechanical behavior, the slit number was the most influential factor.

\section{References}

1. Chung, W.S.; Jung, S. P.; Park, T.W. 2010. Numerical analysis method to estimate thermal deformation of a ventilated disc for automotives, Journal of Mechanical Science and Technology 24: 2189-2195. https://doi.org/10.1007/s12206-010-0905-3

2. Shahzamanian, M.M.; al. 2010. Finite element analysis of thermoelastic contact problem in functionally graded axisymmetric brake disks, Composite Structures 92: 1591-1602. https://doi.org/10.1016/j.ijsolstr.2011.05.003.

3. Okamura, T.; Yumoto, H. 2006. Fundamental Study on Thermal Behavior of Brake Discs, SAE Technical Paper 01-3203. https://doi.org/10.4271/2006-01-3203.

4. Gao, C.H; Lin, X.Z. 2002. Transient temperature field analysis of a brake in a non-axisymmetric three-dimensional model, Journal of Materials Processing Technology 129(1-3): 513-517. https://doi.org/10.1016/S0924-0136(02)00622-2.

5. Li, J.Y.; Barber, J.R. 2002. Solution of transient thermoelastic contact problems by the fast speed expansion method, Wear 265(3-4):402-410. https://doi.org/10.1016/j.wear.2007.11.010.

6. Adamowicz, A.; Grzes, P. 2002. Analysis of disc brake temperature distribution during single braking under non-axisymmetric load, Applied Thermal Engineering 31: 1003-1012. https://doi.org/10.1016/j.applthermaleng.2010.12.016.

7. Duzgun, M. 2002. Investigation of thermo-structural behaviours of different ventilation applications on brake discs. Journal of Mechanical Science and Technology 26: $235-240$. http://doi.org/10.1007/s12206-011-0921-y.

8. Belhocine, A.; Bouchetara, M. 2013. Thermomechanical Behaviour of Dry Contacts in Disc Brake Rotor with a Grey Cast Iron Composition, Thermal Science 17, 2: 599-609. https://doi.org/10.2298/TSCI110826141B.

9. Qi, H. S; A. Day, A. J. 2007. Investigation of disc/pad interface temperatures in friction braking, Wear 262: 505- 513. https://doi.org/10.1016/j.wear.2006.08.027.

10. Djafri, M. 2010.Etude du comportement thermomécanique des disques de frein d'un avion léger, Faculty of
Mechanical Engineering, USTO University, Oran, Algeria.

11. Mackin, T. J.2002.Thermal cracking in disc brakes, engineering failure analyse, Thesis, University of Illinois at Urbara -champaign USA.9:63-76. https://doi.org/10.1016/S1350-6307(00)00037-6.

12. Choi, J.H; Lee, I. 2003.Finite element analysis of transient thermoelastic behaviours in disk brakes, Departement of Aerospace, Korea,Advanced Institute of Science and Technology, Journal of thermal stress 26(3): 223-244. https://doi.org/10.1080/713855891.

13. Droesbeke, J.J; Fine, J.; Saporta, G. 1997. Plans d'expériences - Applications à l'entreprise. Ed. TECHNIP.

14. Everitt, B.1998. The Cambridge Dictionary of Statistics. Cambridge University Press. ISBN 0521593468.

15. Vivier, S. 2002.Stratégies d'optimisation par la méthode des plans d'expériences et application aux dispositifs électrotechniques modélisés par éléments finis. Thèse de doctorat, Ecole Centrale de Lille Université des Sciences et Technologies de Lille, chapitre I, p.60. Available from Internet:

https://tel.archives-ouvertes.fr/tel-00005822/document.

A. Labdi, M. Bouchetara

OPTIMIZATION OF THE THERMAL AND

MECHANICAL BEHAVIOR OF AN AERONAUTICAL BRAKE DISC USING THE DESIGN OF EXPERIMENTS APPROACH

S u m m a r y

The construction of the brake discs is the subject of numerous studies in the field of automotive, railway and aviation. Indeed, it involves the safety of passengers, which is a primary criterion. The research has focused on the contact of two rubbing parts. So various phenomena may occur such as the rise in temperature, wear and noise emissions. In this study, we chose different geometric disc models designed in 3D using Solid Works software, which are imported ANSYS to do the evaluation of the heat transfer coefficients using ANSYS CFX code. Then we proceed to the analysis of the transient thermal behavior of each model and the determination of the equivalent stress. The simulation results provided by the ANSYS software are used to establish several designs of experiments for each one we write the corresponding mathematical model, then we apply ANOVA method and fisher 's analysis to determine the influential factors.

Keywords: Brake disc - heat transfer- Ansys- Von MisesDesign of Experiments -Anova.

Received September 24, 2017 Accepted April 18, 2018 